\title{
Cascade effects of crop species richness on the diversity of pest in- sects and their natural enemies
}

\author{
SHI PeiJian ${ }^{1,2}$, HUI Cang ${ }^{3}$, MEN XingYuan ${ }^{4 *}$, ZHAO ZiHua $^{1}$, OUYANG Fang ${ }^{1}$, GE Feng $^{1 *}$, \\ JIN XianShi ${ }^{2}$, CAO HaiFeng ${ }^{1} \&$ LI B. Larry ${ }^{5}$ \\ ${ }^{1}$ State Key Laboratory of Integrated Management of Pest Insects and Rodents in Agriculture, Institute of Zoology, Chinese Academy of \\ Sciences, Beijing 100101, China; \\ ${ }^{2}$ Key Laboratory of Sustainable Development of Marine Fisheries, Ministry of Agriculture, Yellow Sea Fisheries Research Institute, Chinese \\ Academy of Fishery Sciences, Qingdao 266071, China; \\ ${ }^{3}$ Centre for Invasion Biology, Department of Botany and Zoology, Stellenbosch University, Matieland 7602, South Africa; \\ ${ }^{4}$ Institute of Plant Protection, Shandong Academy of Agricultural Sciences, Jinan 250100, China; \\ ${ }^{5}$ Ecological Complexity and Modeling Laboratory, University of California, Riverside, CA 92521-0124, USA
}

Received September 27, 2013; accepted November 15, 2013; published online June 6, 2014

\begin{abstract}
Understanding how plant species richness influences the diversity of herbivorous and predatory/parasitic arthropods is central to community ecology. We explore the effects of crop species richness on the diversity of pest insects and their natural enemies. Using data from a four-year experiment with five levels of crop species richness, we found that crop species richness significantly affected the pest species richness, but there were no significant effects on richness of the pests' natural enemies. In contrast, the species richness of pest insects significantly affected their natural enemies. These findings suggest a cascade effect where trophic interactions are strong between adjacent trophic levels, while the interactions between connected but nonadjacent trophic levels are weakened by the intermediate trophic level. High crop species richness resulted in a more stable arthropod community compared with communities in monoculture crops. Our results highlight the complicated cross-trophic interactions and the crucial role of crop diversity in the food webs of agro-ecosystems.
\end{abstract}

trophic level, stability, generalized additive model, monoculture, polyculture

Citation: Shi PJ, Hui C, Men XY, Zhao ZH, Ouyang F, Ge F, Jin XS, Cao HF, Li BL. Cascade effects of crop species richness on the diversity of pest insects and their natural enemies. Sci China Life Sci, 2014, 57: 718-725, doi: 10.1007/s11427-014-4681-7

The species richness of natural enemies plays important roles in the functioning and service provision of agroecosystems, even though it can be strongly affected by the cascade effect of population regulation from species of the other trophic levels [1-3]. The relationship between plant species richness and herbivorous arthropod diversity has attracted significant attention [4-11]. However, few studies have examined the food webs at three trophic levels, such as crops, herbivore pests and their natural enemies in certain

*Corresponding author (email: menxy2000@hotmail.com; gef@ioz.ac.cn) agro-ecosystems [12-14].

Root [4] proposed the top-down natural enemy hypothesis (NEH) and the bottom-up resource concentration hypothesis $(\mathrm{RCH})$ to explain the observed diversity of pest insects. Risch [5] tested these two hypotheses, concluding that only the RCH explained the differences in beetle abundances between crop monocultures and polycultures. Siemann [6] found that the number of plant species and their functional groups boosted species richness, but not arthropod abundance. Knops et al. [7] showed that in a tri-trophic system, herbivore diversity and their predators/parasites 
were significantly affected by plant species richness. However, Knops et al. [7] did not consider the potential interactions between the two higher trophic levels.

In agro-ecosystems, studies have examined the effect of plant diversity on grassland arthropod communities $[6,7,15,16]$, but few have considered the effects of crop richness on arthropod diversity, where many are agricultural pests. Agro-ecosystems are closely associated with crop production, with more research required to elucidate all possible interactions in the tri-trophic system of crops, pest insects, and their natural enemies. Therefore, if the NEH holds, polycultures should increase the species richness of natural enemies in agro-ecosystems, reducing the population and species richness of pest insects. Artificially increasing the population of natural enemies, including the introduction of new predators, may reduce the risk of pest outbreaks. In contrast, if the RCH holds, the species richness or density of pest insects would be affected by crop species richness, with natural enemy communities similarly affected by the species richness of pest insects. Therefore, introducing new natural enemies and artificially increasing the population of natural enemies will not reduce pest insect species richness or density. Using data collected from a four-year trial with five different levels of crop species richness, we examined two types of bottom-up interactions. We investigated direct bottom-up interactions between adjacent trophic levels (i.e., between crop species and herbivorous insects, and between the herbivorous insects and their natural enemies) and indirect bottom-up interactions between crop species and the natural enemies of crop herbivores. Our study elucidates all three interactions in this tri-trophic agro-ecosystem, allowing us to test the $\mathrm{RCH}$ and the NEH using field experiments.

\section{Materials and methods}

\subsection{Study design}

The experiment was conducted in a crop field in Yishui County, Shandong Province, China $\left(35^{\circ} 48^{\prime} 05^{\prime \prime} \mathrm{N}\right.$, $\left.118^{\circ} 37^{\prime} 11^{\prime \prime} \mathrm{E}\right)$, encircled by a 2 -m-high brick wall. The field contained 50 plots $(9 \mathrm{~m} \times 9 \mathrm{~m})$, with a $1-\mathrm{m}$ walkway between any two plots. Five levels of crop species richness were planted, with 10 replicates at each level. Each level was defined by the number of crop species, with 1,2, 4, 8, and 16 species per plot. At a given level, the composition of species within one plot (i.e., one replicate) may differ from another plot, but the number of crop species was identical. Each plot contained 22 rows and columns of crop plants, with the same crop species within each row but potentially different crops in adjacent rows. During the experiment, weed species were continually removed and no pesticides were used. The crop species were randomly chosen from 16 commonly grown species in northern China.

During the growing season from 2007 to 2010, arthro- pods were sampled from the crops on 18 days. The ontogenetic growth of crops has been demonstrated [17] allowing us a reliable estimate for the actual growth season. To sample arthropods, we randomly chose one crop column in a plot. The insects were sorted as either pests or their natural enemies using categories from Zhang and Zhao [18]. The crop and arthropod species sampled are listed in Tables S1 and S2 in Supporting Information.

\subsection{Analyses}

We analyzed the effects of plant species richness on the abundances of pest insects and their natural enemies, including the ratio of natural enemy/pest abundance. We used the arcsine square root transformation of the abundance ratio in the analysis of variance following Kuang et al. [19] and Xiao et al. [20].

The relationship between the species richness (and diversity using the Shannon index) of a higher trophic level $(y)$ and a lower trophic level $(x)$ was represented using the following nonlinear model [21]:

$$
y=a x /(1+b x)
$$

where $a$ and $b$ are constants. This equation describes the saturation of $y$ as a function of $x$, becoming linear when $b=0$ [22]. Table 1 exhibits the statistical significances of two model parameters (i.e., $a$ and $b$ ).

In addition, the total abundance of the lower trophic level and the sampling date can also affect $y$. The generalized additive model (GAM; [23,24]) was used to examine the effects of one to four explanatory variables to determine the higher trophic level richness (or diversity). Tables 2 and 3 provide the details of the response variable and the corresponding explanatory variables. To assess the performance of eq. (1), we conducted a GAM using only one explanatory variable $(x)$. To assess the role of species richness at different trophic levels on community stability, we used the coefficient of variation $(\mathrm{CV})$ for species richness by pooling the data. The CV indicates community instability and dynamic over-dispersion $[16,25,26]$. We used the jackknife method to calculate the standard error of the $\mathrm{CV}$ at different levels of plant species richness [27]. We used a nonlinear model to assess the effect of plant species richness on the $\mathrm{CV}$ of pest insect richness and the effect of pest insect richness on the $\mathrm{CV}$ of the natural enemy richness:

$$
\mathrm{CV}=c+d / q,
$$

where $q$ represents the species richness of plants (or pest insects), $c$ and $d$ are constants.

\section{Results}

We found no significant differences in pest insect abundance among the five levels of crop species richness (Figure 1; 
$\left.F_{1881}=1.007, \quad P=0.316\right)$ and natural enemy abundance showed no significant differences among different crop species richness $\left(F_{1881}=0.640, P=0.424\right)$. No significant differences occurred in the abundance ratio (arcsine transformation of the square root) among the levels of crop species richness $\left(F_{1881}=2.068, P=0.151\right)$. However, high crop species richness increased the species richness of pest insects, supporting a greater diversity of natural enemies (Figure 2). In contrast, the relationship between the species richness of plants and natural enemies was weak $\left(R^{2}=0.04\right.$, Table 1$)$. The saturation form of eq. (1) showed a good fit with the observed relationships of species richness at different trophic levels (Table 1).

The GAM showed that both sampling time and $x$ had significant effects on $y$ (Table 2). When selecting one explanatory variable for $x$, the predicted relationship from the GAM between $x$ and $y$ was similar to the saturation form of eq. (1) (Figures 2 and 3), suggesting a good parametric model for exploring the cascade effect across trophic levels. Moreover, high crop species richness resulted in a decrease of the $\mathrm{CV}$ for the species richness of pest insects and their natural enemies (Figure 4A and $\mathrm{C}$ ). The effect of crop richness on the $\mathrm{CV}$ in natural enemy richness was relatively weak (Figure 4B, Table 4), suggesting a more stable arthropod community.

\section{Discussion}

Our results showed that natural enemy species richness was significantly associated with pest insects and this correlation should not be interpreted as top-down pest control [28]. If the NEH holds, we should expect to see a reduction in pest abundance or richness when the richness of their natural enemies increases. In contrast, the study indicated that higher natural enemy species richness was associated with higher species richness of pest insects, contradicting the assumption of top-down pest control in the NEH. Therefore, we should distinguish the association from a causal relationship.

Siemann [6] proposed that increasing predator/parasite diversity may increase herbivore diversity if (i) there are appropriate trade-offs between competitive ability and predator or parasite resistance; (ii) predators switch to feed on more abundant prey species; (iii) prey are spatially aggregated. However, while the natural enemies could in-
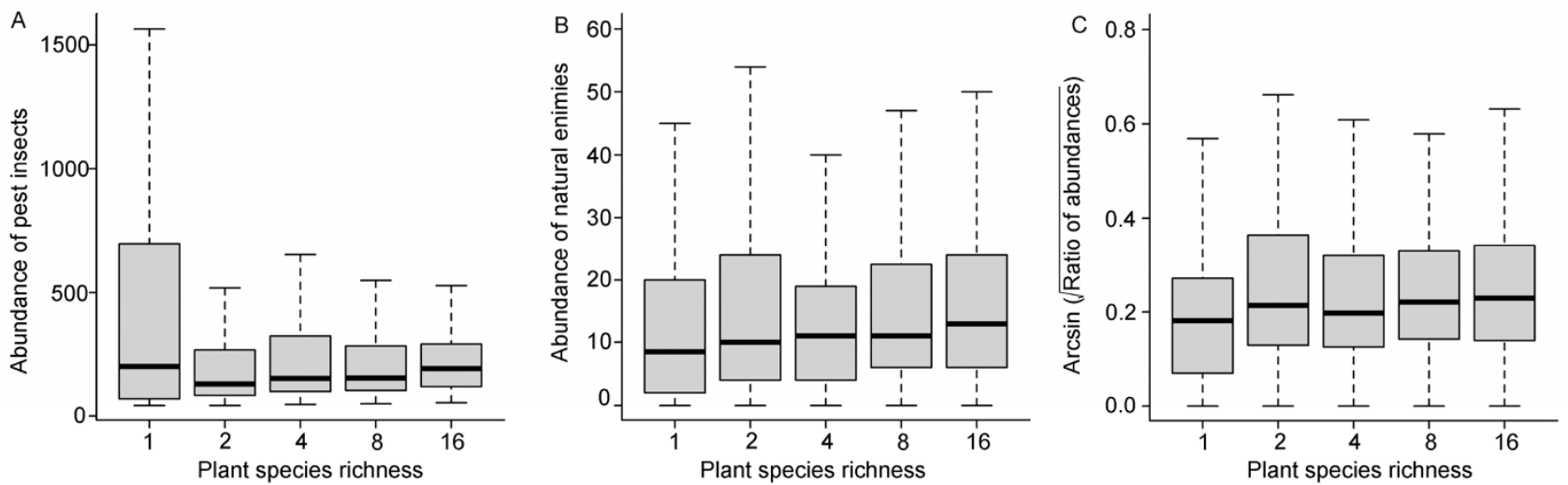

Figure 1 Pest insects and natural enemy abundance at different levels of plant species richness. A, Abundance of pest insects. B, Abundance of natural enemies. C, The arcsine square root transformation of the ratio of the abundance of natural enemies to pest insects.

Table 1 Parameter estimates of the non-linear model of $y=a x /(1+b x)$ for describing the diversity relationship between two trophic levels $(n=883)$

\begin{tabular}{|c|c|c|c|c|c|}
\hline Response vs. Predictor & Parameter & Estimate & $t$ value & $\operatorname{Pr}(>|t|)$ & $R^{2}$ \\
\hline \multirow{2}{*}{$\begin{array}{l}\text { Species richness of pest insects } \\
\text { vs. Plant species richness }\end{array}$} & $a$ & $7.968 \pm 0.620$ & 12.85 & $<0.001$ & \multirow{2}{*}{0.25} \\
\hline & $b$ & $0.707 \pm 0.069$ & 10.30 & $<0.001$ & \\
\hline \multirow{2}{*}{$\begin{array}{l}\text { Shannon index of pest insects } \\
\text { vs. Plant species richness }\end{array}$} & $a$ & $1.269 \pm 0.092$ & 13.85 & $<0.001$ & \multirow{2}{*}{0.28} \\
\hline & $b$ & $0.817 \pm 0.072$ & 11.28 & $<0.001$ & \\
\hline \multirow{2}{*}{$\begin{array}{l}\text { Species richness of natural enemies } \\
\text { vs. Plant species richness }\end{array}$} & $a$ & $10.631 \pm 1.968$ & 5.40 & $<0.001$ & \multirow{2}{*}{0.04} \\
\hline & $b$ & $2.103 \pm 0.437$ & 4.81 & $<0.001$ & \\
\hline $\begin{array}{l}\text { Shannon index of natural enemies } \\
\text { vs. Plant species richness }\end{array}$ & $b$ & $2.243 \pm 0.445$ & 5.04 & $<0.001$ & 0.04 \\
\hline \multirow{2}{*}{$\begin{array}{l}\text { Species richness of natural enemies } \\
\text { vs. Species richness of pest insects }\end{array}$} & $a$ & $0.866 \pm 0.058$ & 14.85 & $<0.001$ & \multirow{2}{*}{0.33} \\
\hline & $b$ & $0.063 \pm 0.011$ & 8.86 & $<0.001$ & \\
\hline \multirow{2}{*}{$\begin{array}{l}\text { Shannon index of natural enemies } \\
\text { vs. Species richness of pest insects }\end{array}$} & $a$ & $0.261 \pm 0.019$ & 13.88 & $<0.001$ & \multirow{2}{*}{0.31} \\
\hline & $b$ & $0.104 \pm 0.015$ & 6.98 & $<0.001$ & \\
\hline
\end{tabular}


Table 2 Using the generalized additive models to interpret species diversity of different trophic levels $(n=883)^{\mathrm{a})}$

\begin{tabular}{|c|c|c|c|c|c|}
\hline Dependent variable & Independent variable (s) & $\begin{array}{c}\text { Degrees of } \\
\text { freedom }\end{array}$ & $F$ value & $P$ value & $R_{a d j}^{2}$ \\
\hline \multirow{4}{*}{ Abundance of pest insects } & $\mathrm{s}$ (Sampling time) & 8.73 & 2.86 & 0.003 & \multirow{4}{*}{0.05} \\
\hline & $\mathrm{s}$ (Species richness of natural enemies) & 1.00 & 0.30 & 0.580 & \\
\hline & $\mathrm{s}$ (Abundance of natural enemies) & 2.71 & 1.23 & 0.300 & \\
\hline & $\mathrm{s}$ (Plant species richness) & 3.99 & 5.32 & $<0.001$ & \\
\hline \multirow{4}{*}{ Abundance of natural enemies } & $\mathrm{s}$ (Sampling time) & 5.86 & 3.17 & 0.005 & \multirow{4}{*}{0.07} \\
\hline & $\mathrm{s}$ (Species richness of pest insects) & 1.00 & 24.62 & $<0.001$ & \\
\hline & $\mathrm{s}($ Abundance of pest insect) & 3.29 & 2.28 & 0.072 & \\
\hline & $\mathrm{s}$ (Plant species richness) & 1.64 & 4.97 & 0.013 & \\
\hline \multirow{4}{*}{ Species richness of pest insects } & $\mathrm{s}$ (Sampling time $)$ & 9.00 & 10.81 & $<0.001$ & \multirow{4}{*}{0.53} \\
\hline & $\mathrm{s}($ Species richness of natural enemies $)$ & 3.39 & 53.49 & $<0.001$ & \\
\hline & s(Abundance of natural enemies) & 1.00 & 0.33 & 0.570 & \\
\hline & $\mathrm{s}$ (Plant species richness) & 3.23 & 96.89 & $<0.001$ & \\
\hline \multirow{2}{*}{ Species richness of pest insects } & $\mathrm{s}$ (Sampling time) & 9.00 & 30.83 & $<0.001$ & \multirow{2}{*}{0.43} \\
\hline & $\mathrm{s}$ (Plant species richness) & 3.32 & 116.86 & $<0.001$ & \\
\hline Species richness of pest insects & $\mathrm{s}$ (Plant species richness) & 3.23 & 91.77 & $<0.001$ & 0.25 \\
\hline \multirow{4}{*}{ Shannon index of pest insects } & $\mathrm{s}$ (Sampling time) & 8.93 & 4.74 & $<0.001$ & \multirow{4}{*}{0.39} \\
\hline & $\mathrm{s}($ Species richness of natural enemies) & 4.22 & 12.35 & $<0.001$ & \\
\hline & $\mathrm{s}$ (Abundance of natural enemies) & 5.40 & 1.71 & 0.117 & \\
\hline & $\mathrm{s}$ (Plant species richness) & 3.94 & 73.66 & $<0.001$ & \\
\hline \multirow{2}{*}{ Shannon index of pest insects } & $\mathrm{s}$ (Sampling time) & 8.97 & 10.25 & $<0.001$ & \multirow{2}{*}{0.34} \\
\hline & $\mathrm{s}$ (Plant species richness) & 3.97 & 93.78 & $<0.001$ & \\
\hline Shannon index of pest insects & $\mathrm{s}$ (Plant species richness) & 3.96 & 85.60 & $<0.001$ & 0.28 \\
\hline \multirow{4}{*}{ Species richness of natural enemies } & $\mathrm{s}$ (Sampling time) & 8.98 & 17.64 & $<0.001$ & \multirow{4}{*}{0.44} \\
\hline & $\mathrm{s}$ (Species richness of pest insects) & 2.93 & 71.93 & $<0.001$ & \\
\hline & $\mathrm{s}($ Abundance of pest insects) & 4.09 & 3.26 & 0.011 & \\
\hline & s(Plant species richness) & 1.00 & 2.13 & 0.145 & \\
\hline \multirow{2}{*}{ Species richness of natural enemies } & $\mathrm{s}$ (Sampling time) & 8.99 & 18.40 & $<0.001$ & \multirow{2}{*}{0.43} \\
\hline & $\mathrm{s}$ (Species richness of pest insects) & 3.08 & 85.08 & $<0.001$ & \\
\hline Species richness of natural enemies & $\mathrm{s}$ (Species richness of pest insects) & 3.50 & 123.40 & $<0.001$ & 0.33 \\
\hline \multirow{4}{*}{ Shannon index of natural enemies } & $\mathrm{s}$ (Sampling time) & 8.97 & 11.02 & $<0.001$ & \multirow{4}{*}{0.39} \\
\hline & $\mathrm{s}$ (Species richness of pest insects) & 3.81 & 54.17 & $<0.001$ & \\
\hline & s(Abundance of pest insects) & 4.01 & 2.34 & 0.0537 & \\
\hline & $\mathrm{s}$ (Plant species richness) & 1.00 & 1.97 & 0.1608 & \\
\hline \multirow{2}{*}{ Shannon index of natural enemies } & $\mathrm{s}$ (Sampling time) & 8.97 & 11.58 & $<0.001$ & \multirow{2}{*}{0.38} \\
\hline & $\mathrm{s}$ (Species richness of pest insects) & 3.90 & 66.05 & $<0.001$ & \\
\hline Shannon index of natural enemies & $\mathrm{s}$ (Species richness of pest insects) & 3.98 & 100.10 & $<0.001$ & 0.31 \\
\hline
\end{tabular}

a) In this table, the first column represents the response variable, and the second column represents the corresponding explanatory variables. s( $)$ represents the smooth function. Here the degrees of freedom are the reference degrees of freedom (see [24] for details).

crease the Shannon diversity index of pest insects by selectively targeting the most abundant pest species, such a top-down effect may be diluted by insect movement among plots and influenced by other environmental disturbances. In large-scale agro-ecosystems, interactions between pest insects and their natural enemies should be stable $[29,30]$.

The saturation form of eq. (1) reflects the functional response between adjacent trophic levels [21] and between indirectly-connected trophic levels via a third intermediate trophic level. Specifically, let $y=a_{1} x /\left(1+b_{1} x\right)$ and $z=a_{2} y /$ $\left(1+b_{2} y\right)$ denote the richness relationships between pest insects and crops, and between natural enemies and pest insects. The functional relationship between natural enemies and crops also follows the saturation form, $z=a_{1} a_{2} x /$ $\left(1+\left(b_{1}+a_{1} b_{2}\right) x\right)$. However, while eq. (1) describes the species richness (and the Shannon index) of natural enemies as a function of crop species richness (Figure 2C and D), the goodness-of-fit test was relatively low (Table 1). Indeed, the GAM results did not support a significant influence of crop species richness on natural enemies, the effect of crop species richness was mainly diluted by the intermediate trophic level (i.e., pest insects).

Our experiments demonstrated that the relationship between two adjacent trophic levels was stronger compared with two nonadjacent trophic levels. Knops et al. [7] found that the $R^{2}$ for herbivore species richness on plant species richness was 0.24 , compared with an $R^{2}=0.16$ from the linear regression between predator/parasite richness and plant 

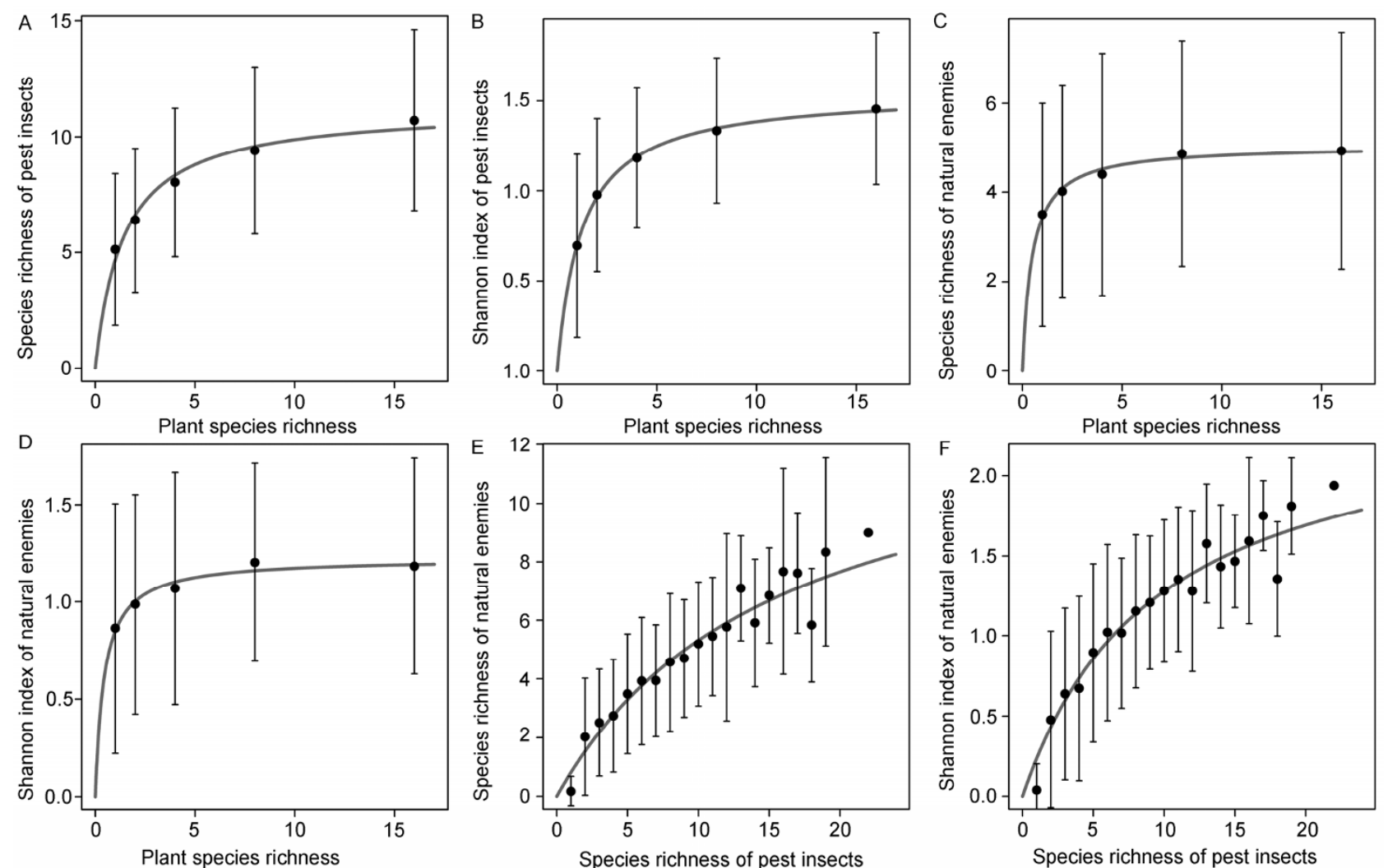

Figure 2 Comparison between the observed and predicted values of species richness and the Shannon index using eq. (1).
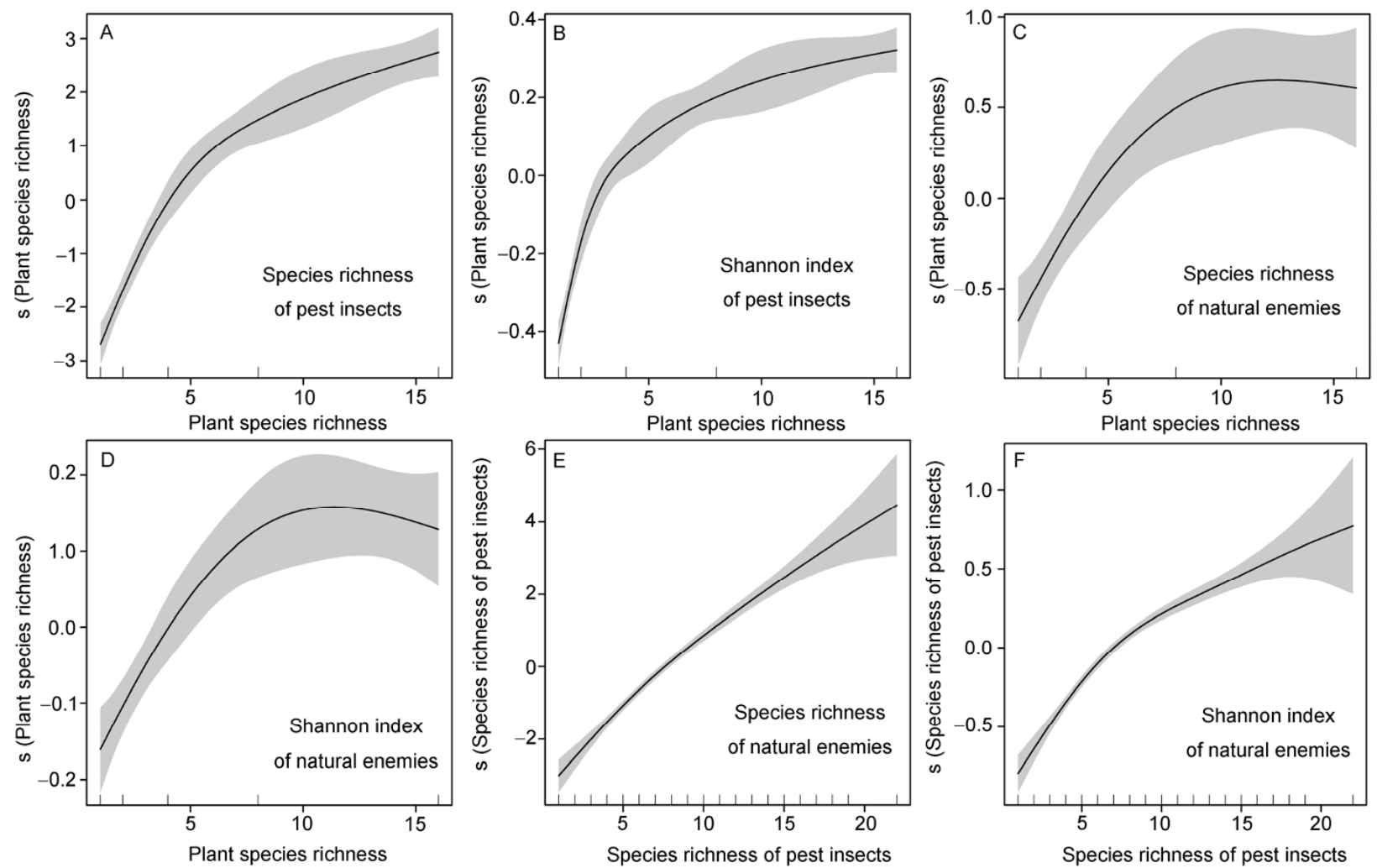

Figure 3 The additive fit of the species richness of pest insects to plant species richness (A), the Shannon index of pest insects to plant species richness (B), the species richness of natural enemies to plant species richness (C); the Shannon index of natural enemies to plant species richness (D); the species richness of natural enemies to the species richness of pest insects $(\mathrm{E})$, and the Shannon index of natural enemies to the species richness of pest insects $(\mathrm{F})$. Here, $\mathrm{s}(\cdot)$ represents a smooth function, with the shaded areas representing point-wise two-times the standard error bands. 

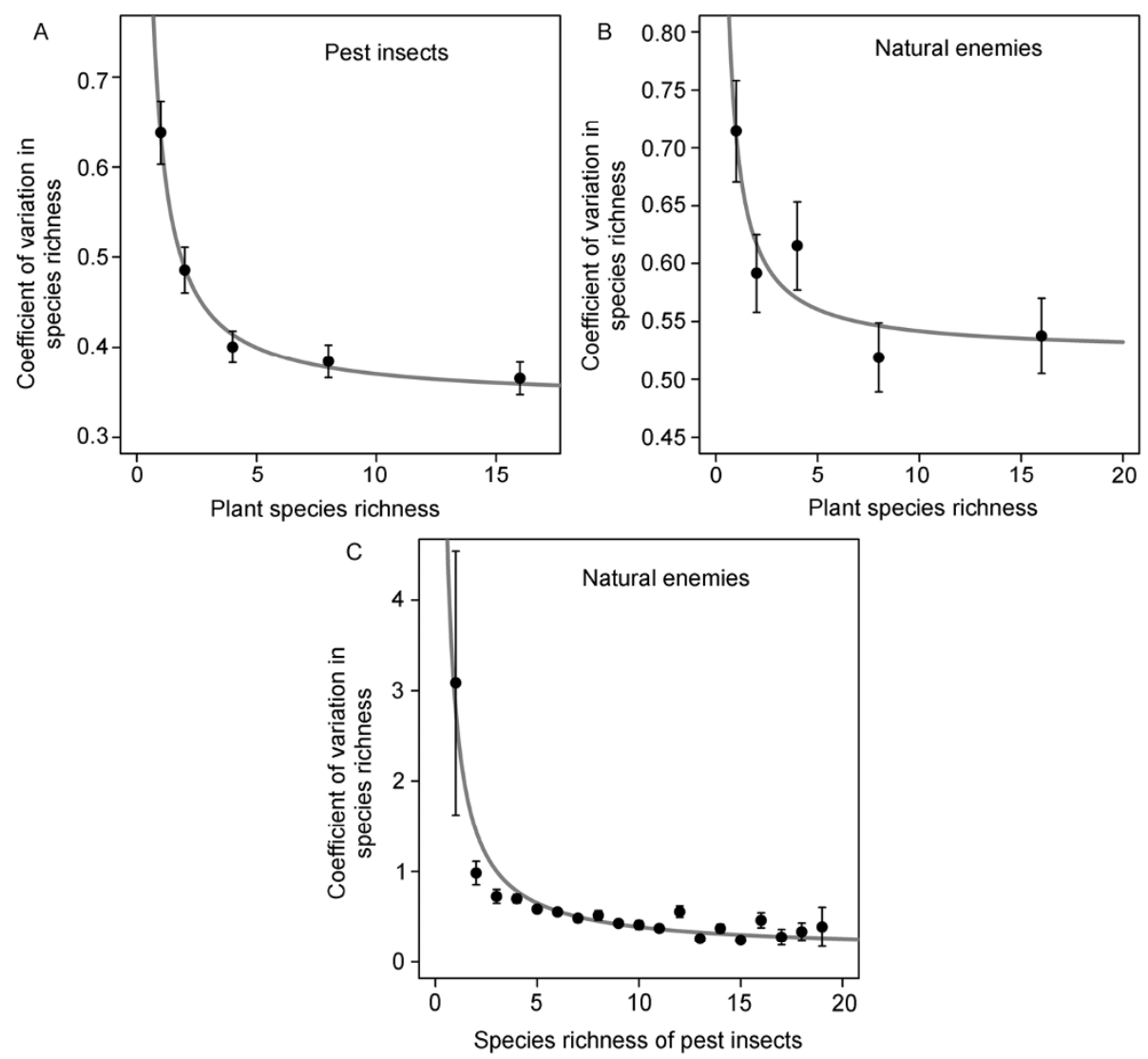

Figure 4 Coefficients of variation in the species richness of pest insects vs. plant species richness (A), the species richness of natural enemies vs. plant species richness (B), and the species richness of natural enemies vs. the species richness of pest insects (C). The points are the coefficients of variation (CVs) calculated by pooling the four-year data. The error bars represent standard errors of CVs calculated using the jackknife method. The curves represent the predicted CVs using eq. (2).

Table 3 Using the generalized additive mixed models with a random effect to interpret species diversity of different trophic levels $(n=883)^{\mathrm{a}}$

\begin{tabular}{|c|c|c|c|c|c|}
\hline Dependent variable & Independent variable (s) & Degrees of freedom & $F$ value & $P$ value & $R_{a d j}^{2}$ \\
\hline \multirow{4}{*}{ Abundance of pest insects } & $\mathrm{s}$ (Sampling time) & 1.00 & 9.63 & 0.002 & \multirow{4}{*}{0.02} \\
\hline & $\mathrm{s}($ Species richness of natural enemies) & 1.00 & 0.52 & 0.471 & \\
\hline & s(Abundance of natural enemies) & 1.00 & 1.86 & 0.173 & \\
\hline & $\mathrm{s}$ (Plant species richness) & 2.69 & 4.97 & 0.003 & \\
\hline \multirow{4}{*}{ Abundance of natural enemies } & $\mathrm{s}$ (Sampling time) & 2.74 & 3.56 & 0.017 & \multirow{4}{*}{0.06} \\
\hline & $\mathrm{s}$ (Species richness of pest insects) & 1.00 & 27.29 & $<0.001$ & \\
\hline & $\mathrm{s}$ (Abundance of pest insects) & 1.72 & 1.39 & 0.240 & \\
\hline & $\mathrm{s}$ (Plant species richness) & 1.00 & 9.52 & 0.002 & \\
\hline \multirow{4}{*}{ Species richness of pest insects } & s(Sampling time) & 1.86 & 4.59 & 0.013 & \multirow{4}{*}{0.49} \\
\hline & $\mathrm{s}($ Species richness of natural enemies) & 2.45 & 87.21 & $<0.001$ & \\
\hline & s(Abundance of natural enemies) & 1.00 & 0.13 & 0.720 & \\
\hline & $\mathrm{s}$ (Plant species richness) & 2.75 & 102.03 & $<0.001$ & \\
\hline \multirow{4}{*}{ Shannon index of pest insects } & s(Sampling time) & 1.95 & 5.50 & 0.005 & \multirow{4}{*}{0.37} \\
\hline & $\mathrm{s}$ (Species richness of natural enemies) & 2.81 & 25.42 & $<0.001$ & \\
\hline & s(Abundance of natural enemies) & 1.00 & 3.96 & 0.047 & \\
\hline & $\mathrm{s}$ (Plant species richness) & 3.32 & 82.08 & $<0.001$ & \\
\hline \multirow{4}{*}{ Species richness of natural enemies } & $\mathrm{s}$ (Sampling time) & 7.72 & 16.06 & $<0.001$ & \multirow{4}{*}{0.44} \\
\hline & $\mathrm{s}$ (Species richness of pest insects) & 2.15 & 96.52 & $<0.001$ & \\
\hline & s(Abundance of pest insects) & 3.50 & 4.50 & 0.002 & \\
\hline & $\mathrm{s}$ (Plant species richness) & 1.00 & 1.49 & 0.222 & \\
\hline \multirow{4}{*}{ Shannon index of natural enemies } & s(Sampling time) & 5.97 & 11.14 & $<0.001$ & \multirow{4}{*}{0.38} \\
\hline & $\mathrm{s}$ (Species richness of pest insects) & 3.31 & 67.32 & $<0.001$ & \\
\hline & $\mathrm{s}$ (Abundance of pest insects) & 3.25 & 2.70 & 0.041 & \\
\hline & $\mathrm{s}$ (Plant species richness) & 1.00 & 2.39 & 0.122 & \\
\hline
\end{tabular}

a) In the generalized additive mixed models, the investigation year is regarded as a random effect (see [24] for details). 
Table 4 Parameter estimates of the non-linear model of $y=c+d / q$ for indicating the community stability

\begin{tabular}{|c|c|c|c|c|c|}
\hline Response vs. predictor & Parameter & Estimate & $t$ value & $\operatorname{Pr}(>|t|)$ & $R^{2}$ \\
\hline \multirow{2}{*}{$\begin{array}{l}\text { Coefficient of variation in Species richness of } \\
\text { pest insects vs. Plant species richness }\end{array}$} & $c$ & $0.341 \pm 0.007$ & 50.99 & $<0.001$ & \multirow{2}{*}{0.99} \\
\hline & $d$ & $0.294 \pm 0.013$ & 22.70 & $<0.001$ & \\
\hline \multirow{2}{*}{$\begin{array}{l}\text { Coefficient of variation in Species richness of } \\
\text { natural enemies vs. Plant species richness }\end{array}$} & $c$ & $0.523 \pm 0.023$ & 22.72 & $<0.001$ & \multirow{2}{*}{0.85} \\
\hline & $d$ & $0.187 \pm 0.045$ & 4.19 & 0.025 & \\
\hline $\begin{array}{l}\text { Coefficient of variation in Species richness of } \\
\text { natural enemies vs. Species richness of pest insects }\end{array}$ & $c$ & $0.121 \pm 0.052$ & 2.31 & 0.034 & 0.93 \\
\hline
\end{tabular}

species richness. We used the nonlinear saturation form (eq. (1)) obtaining a better goodness-of-fit compared with the linear regression used by Knops et al. [7]. Tilman et al. $[31,32]$ used a similar nonlinear form when estimating the effect of species richness on total plant cover and biomass. Haddad et al. [15] found support for this non-linear model.

Haddad et al. [16] demonstrated that high plant diversity stabilized arthropod community diversity across trophic levels, consistent with our results. Moreover, our study indicated that the stability of natural enemies was more directly related to the species richness of pest insects compared with plants. Petermann et al. [33] showed that the highest insect densities and species richness occurred at an intermediate level of plant species richness. In contrast, our study showed that the highest insect species richness (for both pests and their natural enemies) occurred where plant species richness was highest.

We suggest that a strong bottom-up cascade effect occurred across trophic levels, consistent with Petermann et al. [33]. Schmitz [34] reported that spiders actively hunting reduced plant species diversity, while ambush spiders had an opposite effect. Observing a top-down cascade effect in agro-ecosystems is difficult because plant species richness in these systems is relatively stable, except when a pest outbreak occurs. We found that the top-down control imposed by the natural enemies was only detected in pest insect diversity.

Okasnen et al. [35] found that an increase in plant productivity will enhance the role of top-down predation on herbivores, while the impact of herbivory on plant communities decreases. A healthy cropping agro-ecosystem without pest outbreaks means a productive environment for pest insects and relatively low herbivory pressure. Therefore, further investigation is required on the effects of the types of natural enemies (i.e., active hunters' vs. ambush predators) on pest insect diversity. We did not distinguish between natural enemy strategies as we were mainly interested in the relationships among entire trophic levels. The cumulative effect of the natural enemy trophic level on pest insects may differ from the separate effects of active hunters and ambush predators. Similar to Haddad et al. [16], we did not separate the effects of plant species richness on the abundance, diversity and stability of generalist versus specialist herbivores.

Eq. (1) has an asymptote of $y(=a / b)$, indicating the upper limit of species richness in response to the variable $x$. Ac- cordingly, the maximal number of pest insect species in a large polyculture in northern China should be 11 per plot (Figure 2A) and the corresponding maximal species richness of natural enemies should be 5 (Figure 2C). Species composition could vary at different sampling periods and with different crop mixtures. However, the maximal number of arthropod species per plot should be relatively stable. We think this nonlinear saturation form could be used to explore the effects of species diversity on ecosystem function and services.

Generalized linear mixed models have been widely used in community ecology studies [36,37]. The generalized additive mixed model (GAMM) is more flexible for fitting data, compared with the generalized linear mixed models [24], where investigation year is often considered a random effect [38]. In our GAM analyses, we treated the four-year data as replicates. Adding the investigation year as a random mixed-effect, we obtained similar results from the GAMM (Table 3) to those from the GAM (Table 2), suggesting that our results from the GAM were relatively robust.

In conclusion, high plant species richness can support more species of pest insects, further supporting higher diversity of their natural enemies. However, the relationship between two nonadjacent trophic levels, that is, between plant species richness and that of natural enemies is weakened by the intermediate trophic level, dispersal among plots and other environmental disturbances. Moreover, the effects of pest species richness on their natural enemies are time-sensitive, suggesting potential seasonal dynamics within the arthropod community. Overall, our results strongly supported the bottom-up RCH but raised concerns about the top-down control in agro-ecosystems as stated in the NEH. In agro-ecosystems, the $\mathrm{RCH}$ alone can be applied to investigate the cascade effects of crop species richness on the diversity of pest insects and their natural enemies. This may not apply when investigating the cascade effects of crop species richness on the population densities (i.e., abundances) of pest insects and natural enemies.

We are grateful to Yang Bing, Yan Chuan and Li LinMao for their valuable help. This work was partially supported by the National Natural Science Foundation of China (31030012), the National Key Technology Research \& Development Program, China (2013CB127604), and the Special Fund for Agro-scientific Research in the Public Interest, China (201103012). Hui Cang received support from the National Research Foundation, South Africa (76912 and 81825). Li B. Larry was supported by the University of California Agricultural Experiment Station, Riverside, CA, USA. 
1 Morin PJ. Functional redundancy, non-additive interactions, and supply-side dynamics in experimental pond communities. Ecology, 1995, 76: 133-149

2 Finke DL, Denno RF. Predator diversity dampens trophic cascades. Nature, 2004, 429: 407-410

3 Cardinale BJ, Srivastava DS, Duffy JE, Wright JP, Downing AL, Sankaran M, Jouseau C. Effects of biodiversity on the functioning of trophic groups and ecosystems. Nature, 2006, 443: 989-992

4 Root RB. Organization of a plant-arthropod association in simple and diverse habitat: the fauna of collards (Brassica oleracea). Ecol Mono, 1973, 43: 95-124

5 Risch SJ. Insect herbivore abundance in tropical monocultures and polycultures: an experimental test of two hypotheses. Ecology, 1981, 62: $1325-1340$

6 Siemann E. Experimental tests of effects of plant productivity and diversity on grassland arthropod diversity. Ecology, 1998, 79: 2057-2070

7 Knops JMH, Tilman D, Haddad NM, Naeem S, Mitchell CE, Haarstad J, Richie ME, Howe KM, Reich PB, Siemann E, Groth J. Effects of plant species richness on invasion dynamics, disease outbreaks, insect abundances and diversity. Ecol Lett, 1999, 2: 286-293

8 Crist TO, Pradhan-Devare SV, Summerville KS. Spatial variation in insect community and species responses to habitat loss and plant community composition. Oecologia, 2006, 147: 510-521

9 Griffiths GJK, Wilby A, Crawley MJ, Thomas MB. Density-dependent effects of predator species-richness in diversity-function studies. Ecology, 2008, 89, 2986-2993

10 Fornara DA, Tilman D. Ecological mechanisms associated with the positive diversity-productivity relationship in an $\mathrm{N}$-limited grassland. Ecology, 2009, 90: 408-418

11 Soufbaf M, Fathipour Y, Zalucki MP, Hui C. Importance of primary metabolites in canola in mediating interactions between a specialist leaf-feeding insect and its specialist solitary endoparasitoid. Arthropod-Plant Inte, 2012, 6: 241-250

12 Gao F, Ge F, Liu XH, Song Y. Impact of insecticides on the structure and productivity of insect pest and natural enemy communities associated with intercropping in cotton agroecosystems. Int J Pest Manag, 2008, 54: 103-114

13 Wenninger EJ, Inouye RS. Insect community response to plant diversity and productivity in a sagebrush-steppe ecosystem. J Arid Environ, 2008, 72: 24-33

14 Soufbaf M, Fathipour Y, Hui C, Karimzadeh J. Effects of plant availability and habitat size on the coexistence of two competing parasitoids in a tri-trophic food web of canola, diamondback moth and parasitic wasps. Ecol Model, 2012, 244: 49-56

15 Haddad NM, Crutsinger GM, Gross K, Haarstad J, Knops JMH, Tilman D. Plant species loss decreases arthropod diversity and shifts trophic structure. Ecol Lett, 2009, 12: 1029-1039

16 Haddad NM, Crutsinger GM, Gross K, Haarstad J, Tilman D. Plant diversity and stability of foodwebs. Ecol Lett, 2011, 14: 42-46

17 Shi PJ, Men XY, Sandhu HS, Chakraborty A, Li BL, Ouyang F, Sun YC, Ge F. The "general" ontogenetic growth model is inapplicable to crop growth. Ecol Model, 2013, 266: 1-9

18 Zhang SM, Zhao YX. The Geographical Distribution of Agricultural and Forest Insects in China. Beijing: China Agriculture Press, 1996
19 Kuang XJ, Parajulee MN, Shi PJ, Ge F, Xue FS. Testing the rate isomorphy hypothesis using five statistical methods. Insect Sci, 2012, 19: $121-128$

20 Xiao HJ, Wu SH, He HM, Chen C, Xue FS. Role of natural day-length and temperature in determination of summer and winter diapause in Pieris melete (Lepidoptera: Pieridae). Bull Entomol Res, 2012, 102: 267-273

21 Holling CS. Some characteristics of simple types of predation and parasitism. Canad Entomol, 1959, 91: 385-398

22 Zhang F, Hui C, Terblanche JS. An interaction switch predicts the nested architecture of mutualistic networks. Ecol Lett, 2011, 14: 797-803

23 Hastie TJ, Tibshirani RJ, Generalized Additive Models. London: Chapman and Hall, 1990. 136-171

24 Wood SN. Generalized Additive Models: An Introduction with R. London: Chapman and Hall/CRC, 2006. 119-323

25 Lehman CL, Tilman D. Biodiversity, stability, and productivity in competitive communities. Am Nat, 2000, 156: 534-552

26 Hui C, Veldtman R, McGeoch MA. Measures, perceptions and scaling patterns of aggregated species distributions. Ecography, 2010, 33: 95-102

27 Efron B, Tibshirani RJ. An Introduction to the Bootstrap. New York: Chapman and Hall/CRC, 1994

28 Hunter MD, Price PW. Playing chutes and ladders: heterogeneity and the relative roles of bottom-up and top-down forces in natural communities. Ecology, 1992, 73: 724-732

29 Zhao ZH, He DH, Hui C. From the inverse density-area relationship to the minimum patch size of a host-parasitoid system. Ecol Res, 2012, 27: 303-309

30 Zhao ZH, Hui C, Ouyang F, Liu JH, Guan XQ, He DH, Ge F. Effect of inter-annual landscape changes on the interactions between cereal aphids and their natural enemies. Basic Appl Ecol, 2013, 14: 472-479

31 Tilman D, Knops J, Wedin D, Reich P, Ritchie M, Siemann E. The influence of functional diversity and composition on ecosystem processes. Science, 1997, 277: 1300-1302

32 Tilman D, Wedin D, Knops J. Productivity and sustainability influenced by biodiversity in grassland ecosystems. Nature, 1996, 379: 718-720

33 Petermann JS, Müller CB, Weigelt A, Weisser WW, Schmid B. Effect of plant species loss on aphid-parasitoid communities. J Anim Ecol, 2010, 79: 709-720

34 Schmitz OJ. Effects of predator hunting model on grassland ecosystem function. Science, 2008, 319: 952-954

35 Oksanen L, Fretwell SD, Arruda J, Niemela P. Exploitation ecosystems in gradients of primary productivity. Am Nat, 1981, 118: 240-261

36 Bolker BM, Brooks ME, Clark CJ, Geange SW, Poulsen JR, Stevens MHH, White JSS. Generalized linear mixed models: a practical guide for ecology and evolution. Trends Ecol Evol, 2008, 24: 127-135

37 Ives AR, Helmus MR. Generalized linear mixed models for phylogenetic analyses of community structure. Ecol Mono, 2011, 81: 511-525

38 Yang B, Ge F, Ouyang F, Parajulee MN. Intra-species mixture alters pest and disease severity in cotton. Environ Entomol, 2012, 41: 1029-1036

Open Access This article is distributed under the terms of the Creative Commons Attribution License which permits any use, distribution, and reproduction in any medium, provided the original author(s) and source are credited.

\section{Supporting Information}

Table S1 Crop species used in the present study

Table S2 Arthropods investigated in the present study

The supporting information is available online at life.scichina.com and link.springer.com. The supporting materials are published as submitted, without typesetting or editing. The responsibility for scientific accuracy and content remains entirely with the authors. 